RESEARCH PAPER

\title{
Treatment of cerebral cavernous malformations: a systematic review and meta-regression analysis
}

\author{
Michiel H F Poorthuis, ${ }^{1}$ Catharina J M Klijn, ${ }^{1}$ Ale Algra, ${ }^{1,2}$ Gabriel J E Rinkel, ${ }^{1}$ \\ Rustam Al-Shahi Salman ${ }^{3}$
}

- Additional material is published online. To view please visit the journal (http:// dx.doi.org/10.1136/jnnp-2013 307349)

${ }^{1}$ Department of Neurology and Neurosurgery, Brain Center Rudolf Magnus, University Medical Center Utrecht, Utrecht, The Netherlands 2Julius Center for Health Sciences and Primary Care University Medical Center Utrecht, Utrecht, The Netherlands

${ }^{3}$ Division of Clinical Neurosciences, Centre for Clinical Brain Sciences, University of Edinburgh, Western General Hospital, Edinburgh, UK

\section{Correspondence to} Professor Rustam Al-Shahi Salman, Division of Clinical Neurosciences, University of Edinburgh, Western General Hospital, Bramwell Dott Building, Edinburgh EH4 2XU UK; Rustam.Al-Shahi@ed.ac.uk

Received 27 November 2013 Revised 10 February 2014 Accepted 18 February 2014 Published Online First 25 March 2014
CrossMark

To cite: Poorthuis MHF, Klijn CJM, Algra A, et al. J Neurol Neurosurg Psychiatry 2014;85:1319-1323.

\begin{abstract}
Objective The reported effects of treating cerebral cavernous malformations (CCMs) by neurosurgical excision or stereotactic radiosurgery are imprecise and vary between studies.
\end{abstract}

Methods We searched Ovid Medline, EMBASE and The Cochrane Library for peer-reviewed publications of cohort studies describing outcomes of treating 20 or more patients with CCM with at least $80 \%$

completeness of follow-up. Two reviewers extracted data to quantify the incidence of a composite outcome (death, non-fatal intracranial haemorrhage, or new/worse persistent focal neurological deficit) after CCM treatment. We explored associations between summary measures of study characteristics and outcome using Poisson meta-regression analyses.

Results We included 63 cohorts, involving 3424 patients. The incidence of the composite outcome was $6.6(95 \% \mathrm{Cl} 5.7$ to 7.5$)$ per 100 person-years after neurosurgical excision (median follow-up 3.3 years) and $5.4(95 \% \mathrm{Cl} 4.5$ to 6.4$)$ after stereotactic radiosurgery (median follow-up 4.1 years). After neurosurgical excision the incidence of the composite outcome increased with every per cent point increase in patients with brainstem CCM (rate ratio (RR) 1.03, 95\% Cl 1.01 to 1.05$)$, and decreased with each more recent study midyear (RR 0.91, 95\% Cl 0.85 to 0.98) and each per cent point increase in patients presenting with haemorrhage (RR $0.98,95 \% \mathrm{Cl} 0.96$ to 1.00). We did not find significant associations in studies of stereotactic radiosurgery.

Conclusions The reported risks of CCM treatment (and the lower risks of neurosurgical excision over time, from recently bled CCMs, and for CCMs outside the brainstem) compare favourably with the risks of recurrent haemorrhage from CCM. Long-term effects, especially important for stereotactic radiosurgery, are unknown.

\section{INTRODUCTION}

Patients with cerebral cavernous malformations (CCMs) are at risk of epileptic seizures, ${ }^{1}$ intracranial haemorrhage $(\mathrm{ICH})$ and non-haemorrhagic focal neurological deficit (FND). ${ }^{2} \mathrm{CCM}$ treatment with neurosurgical excision or stereotactic radiosurgery (SRS) aims to decrease the risks of these outcomes, but treatment also confers a risk of these same outcomes. ${ }^{3} 4$

CCM treatments have not been compared with each other or with conservative management in a randomised controlled trial and none of the individual comparative observational (non-randomised) studies has reliably demonstrated 'dramatic' beneficial effects of treatment. ${ }^{5}$ Consequently, decisions about CCM treatment rest upon indirect comparisons of lifetime estimates of the untreated course of CCM versus the estimated risks and benefits of treatment.

In the absence of data from randomised trials, data on the effects of treatment from case series can help in the decision about whether to treat a patient with a CCM by estimating overall risks and by identifying groups either at higher chance of a good outcome or at lower risk of a poor outcome. However, most reported series have been small and individually underpowered to determine cohort, patient or CCM characteristics that influence treatment outcome. ${ }^{34}$

Therefore, we set out first to identify all published original case series in order to quantify the risks of CCM treatment with neurosurgical excision or SRS with precision, and second to use meta-regression analysis of these studies to examine determinants of the outcome of treatment.

\section{METHODS}

Protocol

We conducted this systematic review according to a predefined protocol (see online supplementary appendix 1) and report our findings according to the Preferred Reporting Items for Systematic Review and Meta-analyses guidelines. ${ }^{6}$

\section{Search strategy and selection criteria}

We used comprehensive electronic strategies (see online supplementary appendix 2) to search Ovid Medline, EMBASE and The Cochrane Library on 31 July 2012 for articles meeting our predefined eligibility criteria. We crosschecked the bibliographies of included articles to identify additional studies until we did not identify further studies. One reviewer (MHFP) screened titles, abstracts and full text for eligible studies (see online supplementary table S1). We sought original articles published in peer-reviewed journals of cohort studies reporting the arbitrarily chosen number of 20 or more patients of any age with CCM confirmed by MRI or pathological examination in all patients, ${ }^{78}$ who underwent treatment with neurosurgical excision or SRS, and in whom the occurrences of death, ICH or FND were quantified per patient per treatment modality. If the completeness of the cohort's entire follow-up was described and was more than $80 \%$ complete, we included outcomes reported in the entire duration of follow-up. If follow-up was not described, we included cohorts if we could 
extract outcomes that occurred within 30 days of treatment. If a subset of patients in a publication met the eligibility criteria, we included them if we were able to extract outcomes per treatment modality for at least $90 \%$ of this subset of patients. Where multiple publications arose from the same cohort, we included the study with the largest sample size. We included eligible studies published in any language apart from Korean (for which we had no translator). We excluded studies if the proportion of patients in the study population with extracerebral or extracranial CCM exceeded 10\%.

\section{Data extraction}

Two reviewers (MHFP and one of four others) independently extracted the relevant data from the included studies (see online supplementary table S2), and any discrepancies were resolved in consensus meetings by MHFP, CJMK and RA-SS. We collected data on study design, patient demographics, CCM characteristics, presenting symptoms and type of CCM treatment. We extracted data on whether each series reported consecutive or selected patients, the method of follow-up (prospective, retrospective, prospective patient collection with retrospective follow-up or unknown), and whether outcome assessment was done by an independent observer and blinded to treatment. We quantified the occurrence of our composite outcome (death, non-fatal ICH, and non-fatal new or worse non-haemorrhagic persistent FND after CCM treatment, if they were attributed to the CCM or its treatment) during follow-up. If authors did not describe the total duration of follow-up or if more than $20 \%$ of patients were lost to follow-up, we extracted outcome data on the period within 30 days of treatment only. We used authors' descriptions of the occurrence of $\mathrm{ICH}$, because most studies were published before standards for reporting of CCM haemorrhage were published. ${ }^{2}$

\section{Statistical analysis}

We separated our analyses of cohorts according to whether they reported the effects of neurosurgical excision or SRS. We quantified the occurrence of outcomes during the total personyears of follow-up described, or by multiplying the median or mean follow-up period by the total number of treated patients. We calculated outcome event incidence rates and 95\% CIs per 100 person-years. We prespecified the following characteristics of the included cohorts as the baseline covariates of interest: cohort midyear (defined as the middle of the time frame of the years in which treatment took place), average age of the patients at the time of treatment, proportion of female patients, proportion of patients with a brainstem CCM, proportion of patients with a prior symptomatic $\mathrm{ICH}$ from the CCM, and the proportion of children. We assessed differences in proportions of these characteristics between studies describing neurosurgical excision and those describing SRS with Mann-Whitney $U$ tests with a $\mathrm{p}$ value $<0.05$ indicating statistically significant differences. We performed Poisson meta-regression analyses of cohort characteristics on the incidence of the composite outcome. For the assessment of the overall incidence rate, we used the intercept of a Poisson model without covariates. We restricted our analyses to covariates that were reported in at least five cohorts. We assessed the relationship of cohort characteristics to each outcome by calculating adjusted rate ratios (RRs) with corresponding 95\% CIs, adjusting for four prespecified cohort characteristics because of their known or assumed influence on our chosen outcome events: age, sex, proportion of brainstem CCM and proportion of patients who had presented with ICH. We expressed adjusted RRs per $1 \%$ increase in the proportion of patients with a cohort characteristic or per 1-year increase in age or midyear, such that a $1 \%$ change in the characteristic in cohorts resulted in a $(\mathrm{RR}-1 \times 100) \%$ change in the cohorts' outcome. We intended to perform sensitivity analyses restricted to highquality studies (defined as being an inception cohort, a cohort with patients identified at a uniform time point in the disease, having a prospective design, and using independent outcome assessment blind to treatment), if at least five studies met these criteria. To assess consistency of effects across cohorts, we used the I-squared $\left(\mathrm{I}^{2}\right)$ statistic. ${ }^{9}$

\section{RESULTS}

After screening 7415 publications we identified 62 eligible studies reporting on 63 cohorts (see online supplementary figure S1) including 3424 patients with treated CCM with a total of 10029 patient-years of follow-up. Forty-nine cohorts involving 2684 patients reported on neurosurgery (6707 patient-years of follow-up) and 14 cohorts involving 740 patients reported SRS (3322 patient-years of follow-up) with 11 using a Gamma Knife $^{10-20}$ and 3 using a linear accelerator. ${ }^{132122}$

\section{Characteristics of the included studies}

Fifteen (24\%) cohorts explicitly described identifying consecutive patients. Fifty-four $(86 \%)$ cohorts were from single centres and the others were multicentre. Thirty-three (52\%) cohorts were from Europe, 18 (29\%) from Asia, 11 (18\%) from North America and one (2\%) from South America. Five (8\%) were prospective, 38 (60\%) retrospective, 2 (3\%) identified patients prospectively but followed them up retrospectively and 18 (29\%) did not specify their study design. Fourteen cohorts did not describe mean nor median duration of follow-up, but only outcome within 30 days of treatment. In none of the 63 cohorts was the outcome assessment performed by an independent person, blinded to treatment. In the 14 cohorts reporting SRS outcome, the median margin dose was 16 (range 12-25) Gy and the median maximum dose (reported in 11 cohorts) was 27 (range 16-33) Gy. We found statistically significant differences between the proportions of patients in neurosurgical and SRS cohorts in CCM size, CCM site and the frequency of multiple CCMs (table 1).

\section{Composite outcome event rates}

The numbers of cohorts reporting on the different outcome events are given in table 2 (and see online supplementary table S3). Thirty-two cohorts reported on the composite outcome (21 neurosurgery cohorts and 11 SRS cohorts). The composite outcome incidence was 6.1 (95\% CI 5.4 to 6.8) per 100 personyears for all cohorts combined $\left(\mathrm{I}^{2}=81 \%\right), 6.6$ (95\% CI 5.7 to $7.5)$ after neurosurgical excision $\left(\mathrm{I}^{2}=85 \%\right)$ and $5.4(95 \%$ CI 4.5 to 6.4 ) after SRS $\left(\mathrm{I}^{2}=63 \%\right)$.

\section{Associations with the composite outcome}

In 22 cohorts with data on brainstem CCM, age, sex and presentation with $\mathrm{ICH}$, the incidence of the composite outcome increased with every $1 \%$ increase in the proportion of patients with brainstem CCMs (adjusted RR 1.02, 95\% CI 1.01 to 1.03). In 14 cohorts, after neurosurgical excision the adjusted RR was $1.03,95 \%$ CI 1.01 to 1.05 and in 8 cohorts after SRS the adjusted RR was 1.03 , 95\% CI 0.95 to 1.11 (table 3). The incidence of the composite outcome after neurosurgical excision decreased for every 1-year increase in study midyear (adjusted RR $0.91,95 \%$ CI 0.85 to 0.98 ), which differed from the association after SRS $\left(p_{\text {interaction }}=0.003\right)$. The incidence of the 
Table 1 Characteristics of the included cohorts

\begin{tabular}{|c|c|c|c|c|c|c|c|c|c|}
\hline \multirow[b]{2}{*}{ Study characteristics } & \multicolumn{3}{|l|}{ Overall $(n=63)$} & \multicolumn{3}{|c|}{ Neurosurgery $(n=49)$} & \multicolumn{3}{|c|}{ Stereotactic radiosurgery $(n=14)$} \\
\hline & Cohorts $(\%)^{a}$ & Patients & Median (range) & Cohorts $(\%)^{a}$ & Patients & Median (range) & Cohorts $(\%)^{a}$ & Patients & Median (range) \\
\hline Patients treated & $63(100)$ & 3424 & $39\left(11^{b}-260\right)$ & $49(100)$ & 2684 & $39(20-260)$ & $14(100)$ & 740 & $36\left(11^{b}-125\right)$ \\
\hline Duration of follow-up, y & $63(100)$ & 3424 & $2.3(0.1-8.1)$ & $49(100)$ & 2684 & $1.4(0.1-8.1)$ & $14(100)$ & 740 & $4.1(0.8-6.5)$ \\
\hline Mid-year, y & $59(94)$ & 3228 & 1996 (1983-2009) & $46(94)$ & 2572 & 1997 (1983-2009) & $13(93)$ & 656 & 1996 (1990-2001) \\
\hline Age, y & $51(81)$ & 2916 & $36(8-52)$ & $39(80)$ & 2323 & $35(8-52)$ & $12(86)$ & 593 & $37(24-41)$ \\
\hline Female, \% & $52(83)$ & 2808 & $50(29-68)$ & $40(82)$ & 2215 & $50(29-68)$ & $12(86)$ & 593 & $47(35-62)$ \\
\hline Multiple CCMs, \% & $39(62)$ & 2358 & $10(0-25)$ & $31(63)$ & 1814 & $9(0-25)^{*}$ & $8(57)$ & 544 & $15(10-20)^{*}$ \\
\hline Children, \% & $17(27)$ & 836 & $0(0-100)$ & $15(31)$ & 814 & $0(0-100)$ & $2(14)$ & 22 & $18(0-36)$ \\
\hline Size, mm & $23(37)$ & 1506 & $18(12-27)$ & $18(37)$ & 1259 & $19(15-27)^{*}$ & $5(36)$ & 247 & $14(12-20)^{*}$ \\
\hline CCM associated with DVA, \% & $19(30)$ & 960 & $8(0-35)$ & $14(29)$ & 744 & $11(0-35)$ & $5(36)$ & 216 & $5(2-27)$ \\
\hline \multicolumn{10}{|l|}{ CCM location } \\
\hline Total supratentorial, \% & $57(91)$ & 3095 & $73(0-100)$ & $45(92)$ & 2489 & $83(0-100)^{*}$ & $12(86)$ & 606 & $39(0-86)^{*}$ \\
\hline Lobar, \% & $53(84)$ & 2838 & $60(0-100)$ & $42(86)$ & 2252 & $75(0-100)^{*}$ & 11 (79) & 586 & $18(0-64)^{*}$ \\
\hline $\begin{array}{l}\text { Basal ganglia and } \\
\text { thalamus, } \%\end{array}$ & 53 (84) & 2838 & $3(0-42)$ & $42(86)$ & 2252 & $0(0-42) * *$ & 11 (79) & 586 & $18(0-33)^{* *}$ \\
\hline Total infratentorial, \% & $57(91)$ & 3095 & $24(0-100)$ & $45(92)$ & 2489 & $16(0-100)^{*}$ & $12(86)$ & 606 & $61(12-100)^{*}$ \\
\hline Brainstem, \% & $56(89)$ & 3057 & $15(0-100)$ & $44(90)$ & 2451 & $7(0-100)^{*}$ & $12(86)$ & 606 & $46(2-100)^{*}$ \\
\hline Cerebellum, \% & $56(89)$ & 3057 & $0(0-32)$ & $44(90)$ & 2451 & $0(0-32)$ & $12(86)$ & 606 & $5(0-18)$ \\
\hline Presented with ICH, \% & $44(70)$ & 2377 & $71(0-100)$ & $32(65)$ & 1825 & $47(0-100)$ & $12(86)$ & 552 & $90(26-100)$ \\
\hline Presented asymptomatic, \% & $50(79)$ & 2813 & $0(0-23)$ & $37(76)$ & 2165 & $0(0-23)$ & $13(93)$ & 648 & $0(0-11)$ \\
\hline
\end{tabular}

composite outcome after neurosurgical excision decreased with every $1 \%$ increase in the proportion of patients presenting with ICH (adjusted RR 0.98, 95\%CI 0.96 to 1.00 ). We did not find any statistically significant associations with the composite outcome after SRS.

\section{Sensitivity analyses}

We were not able to perform sensitivity analyses with highquality studies, because we only identified three studies with all of our required characteristics, which was below our threshold for performing these analyses.

\section{DISCUSSION}

We found that after neurosurgical excision or SRS the incidence of death, non-fatal symptomatic ICH or non-fatal new or worse non-haemorrhagic persistent FND attributed to CCM or its treatment is around 6 per 100 person-years. For neurosurgical excision outcomes have improved over time, the risks are lower

Table 2 Incidence of the composite outcome (and its constituent events) according to the modality of cerebral cavernous malformation treatment

\begin{tabular}{|c|c|c|c|c|c|c|}
\hline & & Cohorts (\%) & Patients & $\begin{array}{l}\text { Total number of } \\
\text { outcome events/ } \\
\text { Person-years }\end{array}$ & $\begin{array}{l}\text { Median number } \\
\text { per cohort (range) }\end{array}$ & $\begin{array}{l}\text { Outcome event incidence } \\
(95 \% \mathrm{CI}) \text { per } 100 \\
\text { person-years }\end{array}$ \\
\hline All cohorts & $\begin{array}{l}\text { Follow-up, person-years } \\
\text { Composite outcome* } \\
\text { Deaths attributable to CCM or treatment } \\
\text { Deaths not attributed to CCM or treatment } \\
\text { Symptomatic ICH } \\
\text { Persistent FND }\end{array}$ & $\begin{array}{l}63(100) \\
32(51) \\
63(100) \\
61(97) \\
43(68) \\
42(67)\end{array}$ & $\begin{array}{l}3424 \\
1568 \\
3424 \\
3228 \\
2465 \\
2123\end{array}$ & $\begin{array}{l}- \\
313 / 5169 \\
28 / 10029 \\
18 / 9348 \\
160 / 8331 \\
201 / 6290\end{array}$ & $\begin{array}{l}72(1.7-1020) \\
3(0-108) \\
0(0-4) \\
0(0-4) \\
1(0-32) \\
2(0-82)\end{array}$ & $\begin{array}{l}- \\
6.1(5.4-6.8) \\
0.3(0.2-0.4) \\
0.2(0.1-0.3) \\
1.9(1.6-2.2) \\
3.2(2.8-3.7)\end{array}$ \\
\hline $\begin{array}{l}\text { Neurosurgery } \\
\text { cohorts }\end{array}$ & $\begin{array}{l}\text { Follow-up, person-years } \\
\text { Composite outcome } \\
\text { Deaths attributable to CCM or treatment } \\
\text { Deaths not attributed to CCM or treatment } \\
\text { Symptomatic ICH } \\
\text { Persistent FND }\end{array}$ & $\begin{array}{l}49(100) \\
21(43) \\
49(100) \\
48(98) \\
29(59) \\
31(63)\end{array}$ & $\begin{array}{l}2684 \\
1100 \\
2684 \\
2613 \\
1725 \\
1655\end{array}$ & $\begin{array}{r}- \\
198 / 3021 \\
18 / 6707 \\
7 / 6701 \\
53 / 5008 \\
176 / 4143\end{array}$ & $\begin{array}{l}48(1.7-1020) \\
2(0-108) \\
0(0-4) \\
0(0-4) \\
1(0-22) \\
2(0-82)\end{array}$ & $\begin{array}{l}- \\
6.6(5.7-7.5) \\
0.3(0.2-0.4) \\
0.1(0.05-0.2) \\
1.1(0.8-1.4) \\
4.3(3.7-4.9)\end{array}$ \\
\hline $\begin{array}{l}\text { Stereotactic } \\
\text { radiosurgery } \\
\text { cohorts }\end{array}$ & $\begin{array}{l}\text { Follow-up, person-years } \\
\text { Composite outcome } \\
\text { Deaths attributable to CCM or treatment } \\
\text { Deaths not attributed to CCM or treatment } \\
\text { Symptomatic ICH } \\
\text { Persistent FND }\end{array}$ & $\begin{array}{l}14(100) \\
11(79) \\
14(100) \\
13(93) \\
14(100) \\
11(79)\end{array}$ & $\begin{array}{l}740 \\
468 \\
740 \\
615 \\
740 \\
468\end{array}$ & $\begin{array}{r}- \\
115 / 2147 \\
10 / 3322 \\
11 / 2647 \\
107 / 3322 \\
25 / 2147\end{array}$ & $\begin{aligned} 160 & (24.9-675) \\
5 & (1-35) \\
0 & (0-2) \\
0 & (0-3) \\
5 & (0-32) \\
2 & (0-6)\end{aligned}$ & $\begin{array}{c}- \\
5.4(4.5-6.4) \\
0.3(0.2-0.6) \\
0.4(0.2-0.8) \\
3.2(2.7-3.9) \\
1.2(0.8-1.7)\end{array}$ \\
\hline
\end{tabular}

${ }^{*}$ Composite outcome consisted of death, non-fatal symptomatic ICH or non-fatal new or worse non-haemorrhagic persistent FND attributed to CCM or its treatment.

CCM, cerebral cavernous malformation; ICH, intracranial haemorrhage; FND, focal neurological deficit; $\mathrm{Cl}$, confidence interval. 
Table 3 Associations between study characteristics and the incidence of the composite outcome (death, non-fatal ICH or new or worsened persistent focal neurological deficit attributed to CCM or its treatment)

\begin{tabular}{|c|c|c|c|c|c|c|c|c|c|}
\hline \multirow[b]{2}{*}{ Study characteristic } & \multicolumn{3}{|c|}{ All cohorts $(n=63)$} & \multicolumn{3}{|c|}{ Neurosurgery $(n=49)$} & \multicolumn{3}{|c|}{ Stereotactic radiosurgery $(n=14)$} \\
\hline & Cohorts & Events & RR $(95 \% \mathrm{CI})$ & Cohorts & Events & RR $(95 \% \mathrm{CI})$ & Cohorts & Events & RR $(95 \% \mathrm{CI})$ \\
\hline Midyear, y & * & & & 13 & 178 & $0.91(0.85$ to 0.98$)$ & 8 & 62 & $1.03(0.96$ to 1.11$)$ \\
\hline Age, y & 22 & 244 & 1.01 (0.98 to 1.05$)$ & 14 & 182 & 0.99 (0.95 to 1.03$)$ & 8 & 62 & 0.96 (0.65 to 1.41$)$ \\
\hline Female, \% & 22 & 244 & 1.01 (0.99 to 1.03 ) & 14 & 182 & 1.00 (0.98 to 1.02$)$ & 8 & 62 & 1.03 (0.87 to 1.21$)$ \\
\hline Brainstem, \% & 22 & 244 & $1.02(1.01$ to 1.03$)$ & 14 & 182 & $1.03(1.01$ to 1.05$)$ & 8 & 62 & $1.03(0.95$ to 1.11$)$ \\
\hline ICH as presenting symptom, $\%$ & 22 & 244 & $1.00(0.99$ to 1.01$)$ & 14 & 182 & $0.98(0.96$ to 1.00$)$ & 8 & 62 & 1.04 (0.96 to 1.13$)$ \\
\hline Children, \% & 8 & 125 & $1.03(0.98$ to 1.09$)$ & 6 & 122 & $1.08(0.98$ to 1.21$)$ & 2 & 3 & Not estimable \\
\hline
\end{tabular}

All analyses are adjusted for patient age, sex, proportion of brainstem CCM and proportion of patients presenting with haemorrhage, unless stated otherwise. The RRs are expressed per $1 \%$ increase in the proportion of patients with a study characteristic or per 1-year increase in age or midyear.

*We did not analyse the effect of midyear on the composite outcome in all cohorts together because there was a significant interaction between midyear and treatment modality $(\mathrm{p}=0.003)$.

CCM, cerebral cavernous malformation; ICH, intracranial haemorrhage; RR, rate ratio.

in patients presenting with haemorrhage and higher in those with brainstem CCM. For SRS we could not detect associations with outcome. Increasing patient age, within the confines of the ages at which patients have been reported to be treated, does not appear to affect the risks of treatment. The period of follow-up of the studies included in the review was relatively short, and the number of high-quality studies was too small to perform separate analyses restricted to high-quality studies.

Our literature search was extensive, comprehensive, and was only influenced by study quality and suitability for this analysis. By using suitable published studies of CCM treatment outcome, we have been able to identify risk factors for an unfavourable course that could not be investigated in smaller individual cohorts. We used a variety of statistical techniques to account for the variation in reporting follow-up in individual cohorts (to maximise their inclusion); the inclusion of outcomes within only 30 days in 14 studies that did not report the total or average duration of follow-up may have slightly elevated these risks. Unfortunately, only three of the included studies fulfilled our criteria for high-quality studies; none of the included studies performed outcome assessment using an independent observer, and most studies did not report methods and durations of follow-up clearly. Duration of follow-up was relatively short in comparison with the duration over which patients may expect benefit from treatment (table 1 ), indicating the need for longer term follow-up in all studies reporting the effects of neurosurgical excision and SRS. Unfortunately, data on whether resections had been complete or partial could not be analysed as they were not provided in the majority of the included studies. Functional outcome after treatment was reported in 27 cohorts, either on a bespoke scale ( 7 cohorts) or by using a generic functional outcome scale. Five generic outcome scales were used to quantify functional outcome in 20 cohorts, so it was inappropriate to pool them and there were insufficient cohorts per treatment modality to examine associations with outcome on any one generic scale. Reporting of seizures after treatment was insufficient to enable us to examine influences on them reliably, as others have confirmed, ${ }^{23}{ }^{24}$ although some predictors of seizure freedom have been identified by others. ${ }^{25}$

The overall risks of adverse events after neurosurgical excision or SRS may help to guide patient management by informing an indirect comparison of treatment risk versus the estimated risks of CCM events during their untreated clinical course in the short term (although the balance of risks in the long term remains uncertain). ${ }^{26} 27$ The overall $\sim 6 \%$ risk of death or nonfatal stroke after both forms of treatment over 2-3 years of follow-up appears to compare unfavourably with the risk of first-ever ICH from a CCM that has never bled $(2.4 \%$ over 5 years), regardless of the CCM location. However, the shortterm risks of treatment appear to compare favourably with the natural history of recurrent ICH (29.5\% over 5 years, all CCM locations combined). The associations that we have found provide reassurance about the reported safety of neurosurgical excision in people who have recently bled from a CCM, in particular if the CCM is outside the brainstem. However, we have confirmed that brainstem CCMs are the most hazardous to treat with neurosurgical excision, but that this treatment has become safer over recent years (including for brainstem $\mathrm{CCMs}^{28-35}$ ), likely due to increasing surgical experience, technical developments and improved electrophysiological monitoring. Nevertheless, it remains challenging to select individual patients for excision of brainstem CCM based on its location and accessibility, the patient's clinical status and expected rate of bleeding, ${ }^{36}$ and this dilemma would be best addressed in a randomised controlled trial. The available data did not reveal statistically significant associations between study-level patient or CCM characteristics and outcome after SRS, precluding statements about associations between CCM location and SRS outcome to help guide the use of SRS. Although the overall incidence of adverse effects after SRS was similar to neurosurgical excision, there are few data about the safety and long-term effects of SRS, which reinforces the need for the use of SRS for CCM to be restricted to research studies with adequate follow-up to capture the delayed effects of SRS.

Our findings have implications for future research. The lack of high-quality studies with long-term follow-up stresses the need for prospective cohort studies with long-term follow-up and standardised and independent assessment of functional outcome to assess the effects of treatment. Ideally, such cohorts should include a randomised comparison of treatment versus conservative management, or comparison of treatment modalities. Standardised international prospective registries and randomised controlled trials could help determine which treatment strategies are most effective, and for whom.

Acknowledgements The authors are grateful to MW Boele and AS van der Heijden for their help with data acquisition. The authors are grateful to Michael Tin Chung Poon (Chinese), Elena Lebedeva (Russian), Hoshino Takao (Japanese), Carla Ferreira (Portuguese), Adam Kobayashi (Polish), Dániel Bereczki (Hungarian) and Ljiljana Bumbasirevic-Beslac (Serbian), for help with translation. 
Contributors RA-SS and GJER initiated the study. MHFP and RA-SS performed the literature searches. RA-SS and MHFP screened titles and abstracts for eligible studies. MHFP searched bibliographies for additional articles. Uncertainties about eligibility were resolved by discussion with GJER and RA-SS. RA-SS and MHFP designed the data collection form, with inputs from CJMK, AA and GJER. MHFP extracted data from the identified articles, and CJMK, RA-SS and GJER were second reviewers. Discrepancies between extractors were resolved by discussion with CJMK and RA-SS. MHFP, CJMK and AA performed the statistical analyses. All authors interpreted the data. MHFP and RA-SS drafted the manuscript which was critically reviewed and revised for important intellectual content by all authors.

Funding RA-SS was funded by a UK Medical Research Council senior clinical fellowship (G1002605) and CJMK was funded by a Netherlands Heart Foundation Clinical Established Investigator grant (2012 T077).

Competing interests None.

Provenance and peer review Not commissioned; externally peer reviewed.

\section{REFERENCES}

1 Josephson CB, Leach JP, Duncan $\mathrm{R}$, et al. Seizure risk from cavernous or arteriovenous malformations: prospective population-based study. Neurology 2011;76:1548-54.

2 Al-Shahi Salman R, Berg MJ, Morrison L, et al. Hemorrhage from cavernous malformations of the brain: definition and reporting standards. Angioma Alliance Scientific Advisory Board. Stroke 2008;39:3222-30.

3 Niranjan A, Lunsford LD. Stereotactic radiosurgery guidelines for the management of patients with intracranial cavernous malformations. Prog Neurol Surg 2013;27:166-75

4 Ojemann RG, Ogilvy CS. Microsurgical treatment of supratentorial cavernous malformations. Neurosurg Clin N Am 1999:10:433-40.

5 Poorthuis M, Samarasekera N, Kontoh K, et al. Comparative studies of the diagnosis and treatment of cerebral cavernous malformations in adults: systematic review. Acta Neurochir (Wien) 2013;155:643-9.

6 Moher D, Liberati A, Tetzlaff J, et al. Preferred reporting items for systematic reviews and meta-analyses: the PRISMA statement. PLoS Med 2009;6:e1000097.

7 McCormick WF. The pathology of vascular ('arteriovenous') malformations. J Neurosurg 1966;24:807-16.

8 Rigamonti D, Drayer BP, Johnson PC, et al. The MRI appearance of cavernous malformations (angiomas). J Neurosurg 1987;67:518-24.

9 Higgins JP, Thompson SG, Deeks JJ, et al. Measuring inconsistency in meta-analyses. BMJ 2003:327:557-60.

10 Karlsson B, Kihlstrom L, Lindquist C, et al. Radiosurgery for cavernous malformations. J Neurosurgery 1998:88:293-7.

11 Kida Y, Kobayashi T, Tanaka T. Treatment of symptomatic AOVMs with radiosurgery. Acta Neurochir Supp/ 1995;63:68-72.

12 Kida Y. Radiosurgery for cavernous malformations in basal ganglia, thalamus and brainstem. Prog Neurol Surg 2009;22:31-7.

13 Kim DG, Choe WJ, Paek SH, et al. Radiosurgery of intracranial cavernous malformations. Acta Neurochir (Wien) 2002;144:869-78.

14 Kim MS, Pyo SY, Jeong YG, et al. Gamma knife surgery for intracranial cavernous hemangioma. J Neurosurg 2005;102(Suppl):102-6.
15 Kondziolka D, Lunsford LD, Flickinger JC, et al. Reduction of hemorrhage risk after stereotactic radiosurgery for cavernous malformations. J Neurosurg 1995:83:825-31.

16 Liscák R, Vladyka V, Simonová G, et al. Gamma knife radiosurgery of the brain stem cavernomas. Minim Invasive Neurosurg 2000:43:201-7.

17 Liu A, Wang CC, Dai K. [Gamma knife radiosurgery for cavernous malformations]. [Chinese]. Acta Academiae Medicinae Sinicae 2005;27:18-21.

18 Liu KD, Chung WY, Wu HM, et al. Gamma knife surgery for cavernous hemangiomas: an analysis of 125 patients. J Neurosurg Supp/ 2005;102:81-6.

19 Nagy G, Razak A, Rowe JG, et al. Stereotactic radiosurgery for deep-seated cavernous malformations: a move toward more active, early intervention. Clinical article. J Neurosurg 2010;113:691-9.

20 Wang $P$, Zhang $F$, Zhang $H$, et al. Gamma knife radiosurgery for intracranial cavernous malformations. Clin Neurol Neurosurg 2010;112:474-7.

21 Huang YC, Tseng CK, Chang CN, et al. LINAC radiosurgery for intracranial cavernous malformation: 10-year experience. Clin Neurol Neurosurg 2006:108:750-6

22 Tsien C, Souhami L, Sadikot A, et al. Stereotactic radiosurgery in the management of angiographically occult vascular malformations. Int J Radiat Oncol Biol Phys 2001;50:133-8.

23 von der Brelie C, Schramm J. Cerebral cavernous malformations and intractable epilepsy: the limited usefulness of current literature. Acta Neurochir (Wien) 2011:153:249-59.

24 Rosenow F, Alonso-Vanegas MA, Baumgartner C, et al. Cavernoma-related epilepsy: review and recommendations for management - Report of the Surgical Task Force of the ILAE Commission on Therapeutic Strategies. Epilepsia 2013;54:2025-35.

25 Englot DJ, Han SJ, Lawton MT, et al. Predictors of seizure freedom in the surgical treatment of supratentorial cavernous malformations. J Neurosurg 2011;115:1169-74

26 Al-Shahi Salman R, Hall JM, Horne MA, et al. Untreated clinical course of cerebra cavernous malformations: a prospective, population-based cohort study. Lancet Neurol 2012;11:217-24.

27 Flemming KD, Link MJ, Christianson TJ, et al. Prospective hemorrhage risk of intracerebral cavernous malformations. Neurology 2012;78:632-6.

28 Fritschi JA, Reulen HJ, Spetzler RF, et al. Cavernous malformations of the brain stem. A review of 139 cases. Acta Neurochir (Wien) 1994;130:35-46.

29 Wang CC, Liu A, Zhang JT, et al. Surgical management of brain-stem cavernous malformations: report of 137 cases. Surg Neurol 2003;59:444-54.

30 Porter RW, Detwiler PW, Spetzler RF, et al. Cavernous malformations of the brainstem: experience with 100 patients. J Neurosurg 1999;90:50-8.

31 Samii M, Eghbal R, Carvalho GA, et al. Surgical management of brainstem cavernomas. J Neurosurg 2001;95:825-32.

32 Li H, Ju Y, Cai BW, et al. Experience of microsurgical treatment of brainstem cavernomas: report of 37 cases. Neurol India 2009;57:269-73.

33 Hauck EF, Barnett SL, White JA, et al. Symptomatic brainstem cavernomas. Neurosurgery 2009;64:61-70

34 Ferroli $\mathrm{P}$, Sinisi $\mathrm{M}$, Franzini $\mathrm{A}$, et al. Brainstem cavernomas: long-term results of microsurgical resection in 52 patients. Neurosurgery 2005;56:1203-12.

35 de Oliveira JG, Lekovic GP, Safavi-Abbasi S, et al. Supracerebellar infratentorial approach to cavernous malformations of the brainstem: surgical variants and clinica experience with 45 patients. Neurosurgery 2010;66:389-99.

36 Garrett M, Spetzler RF. Surgical treatment of brainstem cavernous malformations. Surg Neurol 2009;72(Suppl 2):S3-9. 